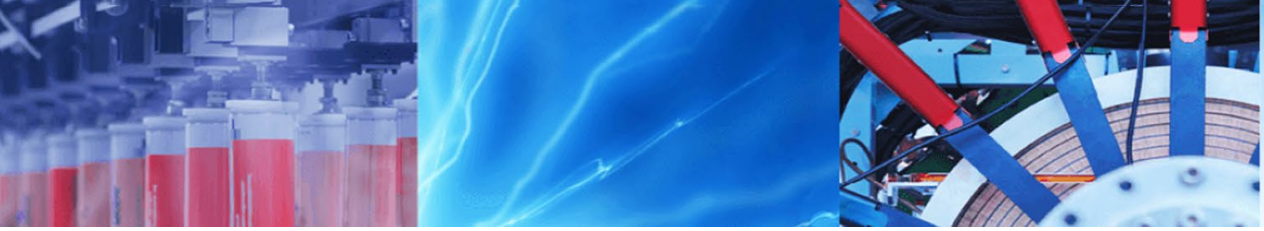

Research Article

\title{
Physicochemical stability evaluation of cosmetic formulations of PVA, starch and MMT clay nanocomposites
}

\author{
Sohini Chakraborty ${ }^{1} \cdot$ V. Anoop ${ }^{1} \cdot$ Nisha George $^{1} \cdot$ T. Bhagyasree $^{1} \cdot$ N. L. Mary ${ }^{1}$
}

(c) Springer Nature Switzerland AG 2019

\begin{abstract}
In the present work, the polymer matrix is comprised of Polyvinyl alcohol and natural polymer starch with the addition of an absorbent clay bentonite. These were effectively blended followed by reinforcement in the form of gold, silver, and zinc oxide nanoparticles. Films were prepared and the dispersion of the nanoparticles was studied by scanning electron microscopy and ultraviolet spectroscopy. The mechanical properties and thermal stability of such nanocomposites as compared to the polymeric blend was studied and an enhancement in properties was observed. Furthermore the use of PVA, bentonite and these nanoparticles in facial masks led to the investigation of cosmetic applications of the polymer nanocomposites thus prepared. This composition was found to be stable in face masks for a period of 12 weeks and reported no irritation when applied to the skin.
\end{abstract}

Keywords Polymer nanocomposites $\cdot$ Cosmetic formulations $\cdot$ Bentonite $\cdot$ Stability studies

\section{Introduction}

Polymer nanocomposites with the unique combination of organic and inorganic counterparts results in diversified application performance [1]. This approach represents a merger between the traditional organic and nanosized inorganic materials, resulting in compositions that are truly hybrid [2]. With the increasing emphasis on biodegradable and natural polymers to sustain the environment, the usage of such polymers for various applications has gained momentum over the years [3]. Natural polymers like starch are present in abundance in the environment but lack good physical and mechanical properties when compared to synthetic polymers [4]. Thus blending the two can prove effective in terms of enhanced properties. Polyvinyl Alcohol (PVA) is a synthetic polymer with excellent film forming ability, biodegradability and mechanical properties. Physical properties of the polymer influences its molecular weight and generally higher the molecular weight, greater will be its physical properties. PVA also shows excellent compatibility with Starch which can be mainly attributed to the possibility of a hydrogen bonding between the -OH groups of the Starch and PVA [5]. Montmorillonite (MMT) clay has been used as an effective filler in many cases to obtain enhancement in properties [6]. Not only do these films exhibit good thermal and mechanical properties, but these components also individually are seen to have applications in the cosmetic field. PVA works well in peel-off masks due to their excellent film-forming properties and it helps to remove dead cells and moisturizes the skin $[5,7]$. MMT Clay, Bentonite on the other hand absorbs the natural sebum off the skin and hence works effectively for oily skin $[8,9]$. Nanomaterials with the properties of better UV protection, greater penetration in the skin, enhanced colour and long-lasting effects has the potential to be used in cosmetic products [10]. Zinc oxide ( $\mathrm{ZnO})$ has an excellent UV filtering property [11] and Silver $\mathrm{Ag}$ ) and Gold $\mathrm{Au}$ ) nanoparticles have antibacterial properties which renders it useful for cosmetic applications [12, 13]. The combined usage of all these materials is expected to show an overall enhancement in the parameters which are taken into consideration for cosmetic applications.

N. L. Mary, maryterrysmc@gmail.com | 'Department of Chemistry, Stella Maris College, Chennai 600086, India.

SN Applied Sciences (2019) 1:581 | https://doi.org/10.1007/s42452-019-0607-0

Received: 1 February 2019 / Accepted: 13 May 2019 / Published online: 17 May 2019 
In the present paper, PVA, Starch and Bentonite have been effectively blended with reinforcements in the form of nanoparticles such as $\mathrm{ZnO}, \mathrm{Au}$ and $\mathrm{Ag}$ and have been solution casted to form films. The morphology of the films was studied using scanning electron microscopy. The interactions between the polymer matrix and the nanoparticles were studied using UV-Visible spectroscopy. The thermal resistance and the mechanical strength of these films were also observed and a comparison was drawn based on the results obtained. The physical stability of the blend solution incorporated in a base face mask formulation was assessed and it was found to be stable for a period of 12 weeks. The sensory evaluation showed good results and no skin irritancy.

\section{Materials and methods}

\subsection{Materials used}

Polyvinyl alcohol (PVA, $\left.\bar{M}_{w}=1,45,000\right)$, trisodium citrate, chloroauric acid $\left(\mathrm{HAuCl}_{4}\right)$, silver nitrate $\left(\mathrm{AgNO}_{3}\right)$, sodium borohydride $\left(\mathrm{NaBH}_{4}\right)$ and Potato Starch $\left(\bar{M}_{w}=342\right)$ were purchased from Sigma Aldrich and were used as received. Milli $Q$ water was used as solvent.

\subsection{Preparation of gold nanoparticles (Au NPs)}

$10 \mathrm{mM}$ standard solution of $\mathrm{HAuCl}_{4} \cdot 3 \mathrm{H}_{2} \mathrm{O}$ was diluted to $10 \mathrm{~mL}$ using milli-Q water and allowed to boil for 2-3 min. $0.5 \%$ of trisodium citrate (stabilizing and reducing agent) was added and heated to boiling till the appearance of pale purple colour. The solution was stirred constantly and cooled to room temperature. The formation of gold nanoparticle was indicated by a change to wine red colour [14].

\subsubsection{Preparation of silver nanoparticles (Ag NPs)}

Silver nanoparticles have been synthesized via wet chemical reduction route. In this method, sodium lauryl sulphate was dissolved in $0.01 \%$ solution of silver nitrate by sonication for $10 \mathrm{~min}$. An aqueous solution of $\mathrm{NaBH}_{4}$ cooled at $0{ }^{\circ} \mathrm{C}$, was injected rapidly into the mixture under vigorous stirring. Rapid colour change from colourless to yellowish brown was observed on sonication for about $5 \mathrm{~min}$ indicating the formation of silver nanoparticle [15].

\subsubsection{Preparation of $\mathrm{ZnO}$ nanoparticles ( $\mathrm{ZnO}$ NPs)}

Sol-gel method was used to prepare $\mathrm{ZnO}$ nanoparticles [16].

Zinc nitrate and Citric acid (1:2 ratio) was dissolved in minimum amount of water and made into a paste. The resultant precipitate was washed with double distilled water and heated up to $110^{\circ} \mathrm{C}$ using a heating mantle for an hour. White coloured $\mathrm{ZnO}$ nanoparticles was obtained.

\subsection{Preparation of nanocomposite films}

\subsubsection{PVA/starch/bentonite (PSB film)}

The nanocomposite films were prepared by solution casting method [17].

PVA $(3 \mathrm{~g})$ was dissolved in $100 \mathrm{~mL}$ water at $70{ }^{\circ} \mathrm{C}$ with constant stirring. Starch $(3 \mathrm{~g})$ was gelatinized in $100 \mathrm{~mL}$ water. PVA, Starch and Bentonite were taken in the volume ratio of 3:2:1 and blended together by placing it in an ultrasonicator for $20 \mathrm{~min}$. A homogenous mixture was obtained. $20 \mathrm{~mL}$ of this solution was casted in the petri dish of diameter $90 \mathrm{~mm}$ to obtain the composite film. Curing of the films was done at room temperature (Table 1).

\subsection{Preparation of nanocomposite films}

The prepared nanoparticles were used to synthesise the nanocomposite film by solution casting method. PVA, Starch and Bentonite were taken in the volume ratio of 3:2:1 and blended together by placing it in an ultrasonicator for $20 \mathrm{~min} .0 .01 \mathrm{wt} \%$ of $\mathrm{Au} / \mathrm{Ag} / \mathrm{ZnO}$ NPs was added to the above composition. Homogeneity of the solution was ensured by sonicating it for an additional $10 \mathrm{~min}$. These solutions were casted in the petri dish to obtain nanocomposite films. Curing of the films was done at room temperature.

\subsection{Cosmetic stability evaluation}

\subsubsection{Preparation of the face mask formulation (Code- 1 )}

The different ingredients in each of the phases along with their specific roles have been tabulated in Table 2 .

The total quantity of demineralised water along with the Phase A ingredients were added into a vessel slowly with homogenization. The mixture was heated to $70-80^{\circ} \mathrm{C}$ and further homogenized. The phase $B$ ingredients were weighed in a separate vessel and heated to $75^{\circ} \mathrm{C}$. Phase $\mathrm{B}$ was slowly added to phase $A$ in vacuum. The mixture was homogenized at $3000 \mathrm{rpm}$ and $650 \mathrm{~Pa}$. After $30 \mathrm{~min}$, phase

Table 1 Polymer nanocomposite films and their sample codes

\begin{tabular}{lll}
\hline Sl. no. & Sample code & Polymer film \\
\hline 1. & PSB-Au & PVA/starch/bentonite/Au \\
2. & PSB-Ag & PVA/starch/bentonite/Ag \\
3. & PSB-ZnO & PVA/starch/bentonite/ZnO
\end{tabular}


Table 2 Raw materials and their quantities required for face mask formulation

\begin{tabular}{|c|c|c|c|c|c|c|c|}
\hline Phase & Raw materials & Functions & Code 1 & Code 2 & Code 3 & Code 4 & Code 5 \\
\hline \multirow[t]{7}{*}{ Phase "A" } & Aqua/water & Dilutent & Qs to 100 & Qs to 100 & Qs to 100 & Qs to 100 & Qs to 100 \\
\hline & Magnesium aluminum silicate & Stabilizer & 1.00 & 1.00 & 1.00 & 1.00 & 1.00 \\
\hline & Multani mitti & Filler & 30.0 & 30.0 & 30.0 & 30.0 & 30.0 \\
\hline & Bentonite & Stabilizer & 5.0 & 5.0 & 5.0 & 5.0 & 5.0 \\
\hline & Allantoin & Skin soothing agent & 0.10 & 0.10 & 0.10 & 0.10 & 0.10 \\
\hline & Titanium dioxide & Opacifier & 3.00 & 3.00 & 3.00 & 3.00 & 3.00 \\
\hline & Disodium EDTA & Chelating agent & 0.050 & 0.050 & 0.050 & 0.050 & 0.050 \\
\hline \multirow[t]{3}{*}{ Phase "B" } & Cetostrearyl alcohol & Thickener & 15.00 & 15.00 & 15.00 & 15.00 & 15.00 \\
\hline & Polysorbate-60 & Emulsifier & 5.00 & 5.00 & 5.00 & 5.00 & 5.00 \\
\hline & Isopropylmyristate & Emollients & 1.00 & 1.00 & 1.00 & 1.00 & 1.00 \\
\hline \multirow[t]{2}{*}{ Phase "C" } & Glycerin & Moisturiser & 10 & 10 & 10 & 10 & 10 \\
\hline & Xanthan gum & Thickener & 0.40 & 0.40 & 0.40 & 0.40 & 0.40 \\
\hline \multirow[t]{4}{*}{ Phase “D” } & Methylparaben & Preservative & 0.25 & 0.25 & 0.25 & 0.25 & 0.25 \\
\hline & Propylparaben & Preservative & 0.15 & 0.15 & 0.15 & 0.15 & 0.15 \\
\hline & Phenoxyethanol & Preservative & 0.50 & 0.50 & 0.50 & 0.50 & 0.50 \\
\hline & Propylene glycol & Moisturiser & 0.50 & 0.50 & 0.50 & 0.50 & 0.50 \\
\hline \multirow[t]{2}{*}{ Phase "E" } & Sodium laureth sulfate & Cleaning agent & 1.0 & 1.0 & 1.0 & 1.0 & 1.0 \\
\hline & DMDM hydantoin & Preservative & 0.30 & 0.30 & 0.30 & 0.30 & 0.30 \\
\hline \multirow[t]{2}{*}{ Phase "F" } & Licorice (glycyrrhiza glabra) concentrate & Melanin Inhibitor & 0.10 & 0.10 & 0.10 & 0.10 & 0.10 \\
\hline & Banana(Musa sapientum) concentrate & Skin Nutrient & 0.10 & 0.10 & 0.10 & 0.10 & 0.10 \\
\hline \multirow[t]{3}{*}{ Phase "G" } & Perfume & Fragrance & 0.30 & 0.30 & 0.30 & 0.30 & 0.30 \\
\hline & Triclosan & Anti bacterial agent & 0.1 & 0.1 & 0.1 & 0.1 & 0.1 \\
\hline & BHT & Anti oxidant & 0.03 & 0.03 & 0.03 & 0.03 & 0.03 \\
\hline Phase "H" & $\mathrm{Cl}: 19140$ & Colourant & 0.10 & 0.10 & 0.10 & 0.10 & 0.10 \\
\hline \multirow[t]{4}{*}{ Phase "I" } & PSB & Nano active & 0.00 & 1.00 & 0.00 & 0.00 & 0.00 \\
\hline & PSB-Au & Nano active & 0.00 & 0.00 & 1.00 & 0.00 & 0.00 \\
\hline & PSB-Ag & Nano active & 0.00 & 0.00 & 0.00 & 1.00 & 0.00 \\
\hline & PSB-ZnO & Nano active & 0.00 & 0.00 & 0.00 & 0.00 & 1.00 \\
\hline
\end{tabular}

Qs Quantity sufficient

D was added to the above mixture. It was homogenized and cooled. Once temperature reached to $50-60^{\circ} \mathrm{C}$, phase $E$ was added into the vessel containing the above mixture. It was homogenized for and cooled. Once temperature reached to $40-45^{\circ} \mathrm{C}$, phase $\mathrm{F}$ was added and homogenized and was taken out of vacuum. BHT and Triclosan were dissolved in perfume. Once temperature reached to $40^{\circ} \mathrm{C}$, phase $\mathrm{G}$ and phase $\mathrm{H}$ was added to the above mixture and complete dispersion was ensured.

The final step was to add the polymer nanocomposites under homogenization to formulate the codes 2, 3, 4 and 5.

\subsection{Sensory evaluation}

The study was conducted using a 10 member expert panel of trained women who used a known amount of the test formulations and compared it to the conventional vanishing cream $[18,19]$. The panelists were given coded samples in a randomized order. The results were tabulated based on parameters such as skin even tone, non-oily look, brightness, creamy feel, thickness, etc. (Figs. 5 and 6).

\subsection{Physical stability test}

To assess the product's physical stability all five products (one base and four samples) were kept at different storage conditions. $30 \mathrm{~g}$ of each product was filled in HDPE tube and kept in different storage conditions such as at room temperature, $4{ }^{\circ} \mathrm{C}, 45^{\circ} \mathrm{C}, 50^{\circ} \mathrm{C}$ and $40^{\circ} \mathrm{C}$ at a relative humidity of $70 \%$ [20] (Table 3).

\subsection{Characterization}

Jasco V-750 instruments were used to characterise the composite samples. Scanning electron microscopic (SEM) images were taken in a FEI QUANTA-200 scanning electron microscope to understand the surface morphology of the 
Table 3 Methods of analyzing the physical characteristics

\begin{tabular}{lll}
\hline S. no. & Physical characteristics & Method of analysis \\
\hline 1 & Colour & Visual \\
2 & Appearance & Visual \\
3 & Odour & Olfactory \\
4 & $\mathrm{pH}$ & BIS:6608:2009 \\
& & Annex B \\
5 & Viscosity @ $30^{\circ} \mathrm{C}$, TE spindle. & BIS:13360(Part 1 I/ \\
& S95, 0.60 RPM/45 s & Set ISO 2555: \\
& & 1969) \\
\hline
\end{tabular}

film. Universal Testing Machine (UTM) was employed for testing the mechanical properties of the nanocomposite films. The Shimadzu AGS-X 500 mm extended frame UTM was used. Thermo gravimetric analysis of the films was carried out using a (TGA)-TA Q 600 thermal analyzer.

\section{Results and discussion}

\subsection{Morphology of the nanocomposite film}

The morphology of the polymer films was studied using SEM analysis.
Figure 1a shows the SEM image of the PSB film wherein the aliminosilicate layers of the bentonite dispersed in the polymer matrix can be easily realized. The subsequent images show the dispersion of the nanoparticles in the PSB blend matrix. There is slight aggregation of the nanoparticles in the PSB-Au film (Fig. 1b) which results due to the binding energy of the nanoparticles which makes them interconnected to each other [21]. From the Fig. $1 c, d$, it can be observed that there is a good dispersion of nanoparticles in the polymer matrix. The white spots represent the nanoparticles which are perceived to be present in the polymer matrix without agglomeration.

\subsection{UV-Vis spectroscopy}

The optical absorbance of the films was studied using a Solid UV-Vis Spectrometer (Fig. 2).

The incompletely dispersed nanoparticles and the clay aggregates usually causes scattering of the light and the optical clarity of the films maybe reduced [22]. The nanoparticles here show good dispersion in the polymer matrix as suggested by the peaks characteristic to the nanoparticles obtained in the UV-Vis spectra of the films.
Fig. 1 SEM images of nanocomposite films a PSB b PSBAu c PSB-Ag d PSB-ZnO
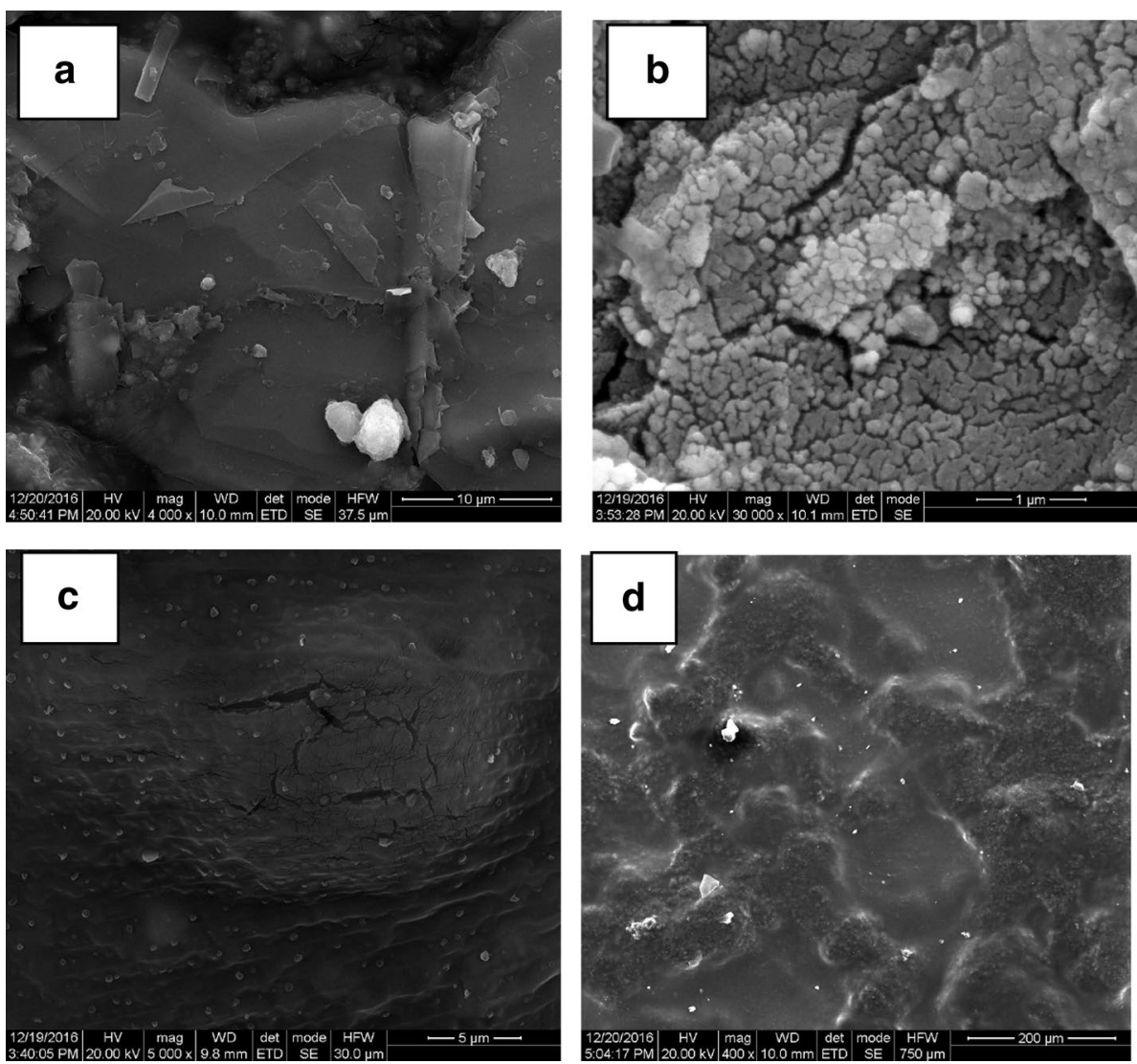
Au NPs shows a strong absorption band in the region of 550-600 nm which can be clearly identified in the spectra of PSB-Au. Silver nanoparticles have a characteristic peak at $420 \mathrm{~nm}$ which is represented in the spectra of PSB-Ag. Similarly, the spectra of PSB-ZnO show peaks at the UV region at around $360 \mathrm{~nm}$. There is no absorption peak for the pure polymer blend in the range of $300-600 \mathrm{~nm}$. This can be regarded as the evidence for efficient incorporation of the nanoparticles in the polymer matrix.

\subsection{Mechanical properties}

The figure below (Fig. 3) shows the tensile graphs of the polymer nanocomposite films.

The films reinforced with the nanoparticles show increase in tensile strength. The tensile strength of PSB-Au
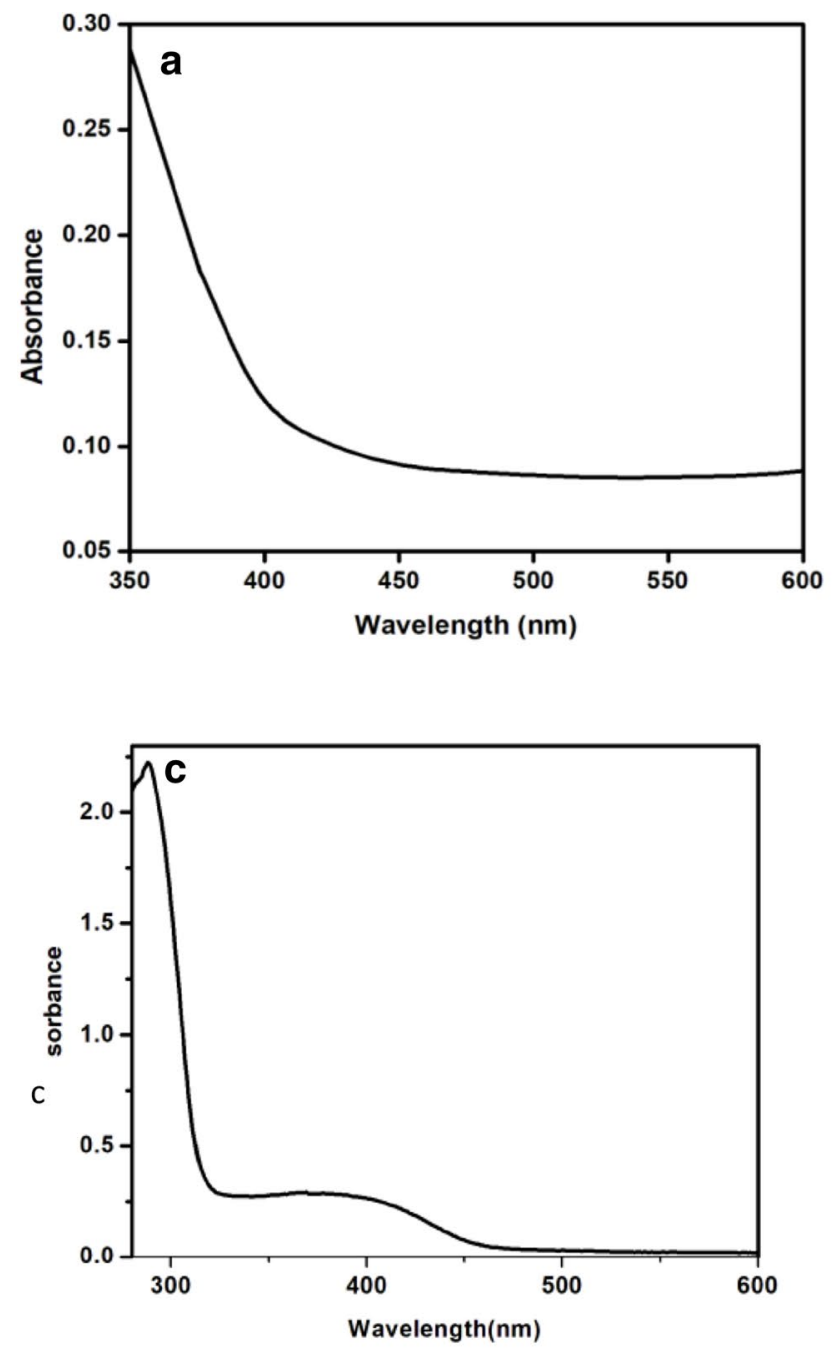

Fig. 2 UV-Vis Spectra of a PSB b PSB-Au c PSB-Ag d PSB-ZnO shows the minimum value amongst the nanocomposites which can be due to the agglomeration of the Au NPs in the polymer matrix as suggested by the SEM data. PSB$\mathrm{ZnO}$ shows the highest tensile strength among all the polymer samples. This indicates that the filler material is rigid and consequently there is good adhesion between the phases.

The tensile strength increases on addition of nanoparticles (Table 4) to the polymer matrix however it's subject to the complete dispersion of the nanoparticles in the polymer matrix [22].

\subsection{Thermal properties}

TGA curves of pure blend and the nanocomposites revealed three main weight loss regions as shown in Fig. 4. The 1 st and the 2 nd degradation peak appeared at
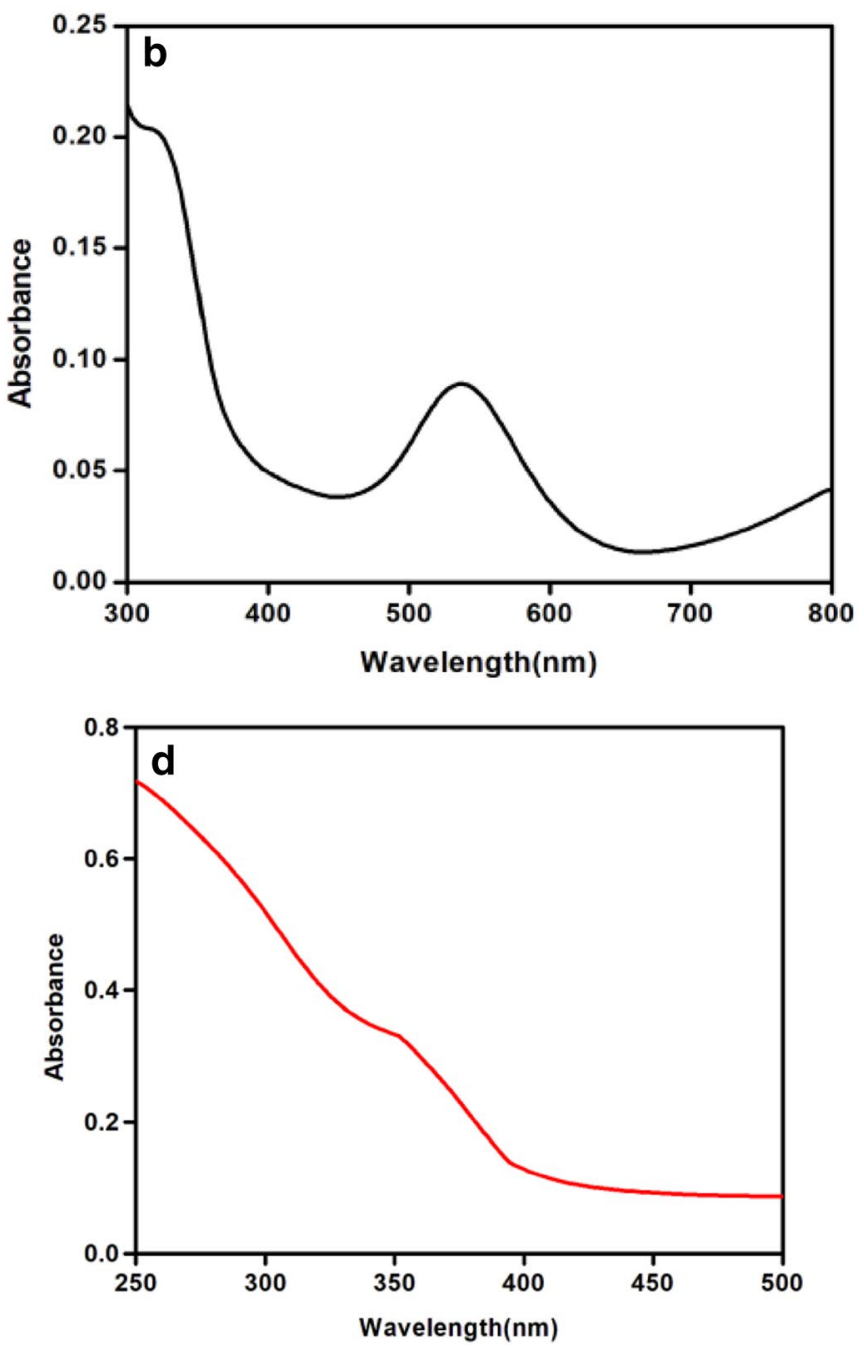


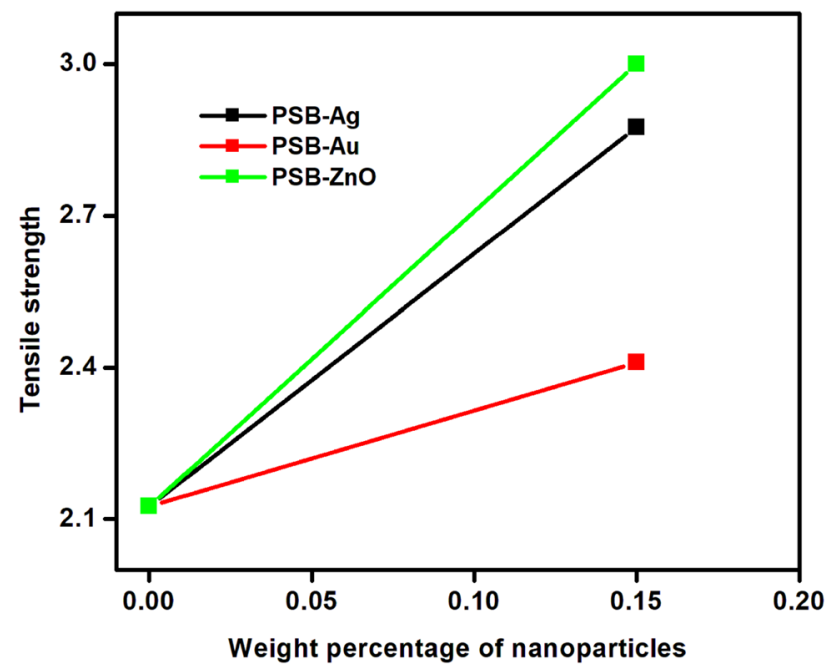

Fig. 3 Tensile strength versus weight percentage of nanoparticles for the polymer blend films

Table 4 Mechanical properties of polymer films

\begin{tabular}{ll}
\hline Film & $\begin{array}{l}\text { Tensile } \\
\text { strength } \\
(\mathrm{MPa})\end{array}$ \\
\hline PSB & 2.125 \\
PSB-Ag & 2.875 \\
PSB-Au & 2.4 \\
PSB-ZnO & 3.00 \\
\hline
\end{tabular}

$70.66^{\circ} \mathrm{C}$ and $303.58^{\circ} \mathrm{C}$ respectively for starch-PVA $50 / 50$ blend. [23].

For PSB, the first degradation peak is observed at a value greater than $100^{\circ} \mathrm{C}$. The thermal stability is maximum for the blend with ZnO NPs. The figure below shows the TGA curve of the polymer blend films.

The final residue is maximum in case of PSB-ZnO at $6.01 \%$ which is due to the powder consistency of the nanoparticles used for the film formation. These results validate the thermal stability of the nanocomposites and are tabulated as follows (Table 5).

Apart from the aforementioned reasons, the improvement in thermal stability can also be due to the fact that the filler material leaves some residue and the thermal resistance is enhanced because of a strong polymericinorganic char. This char is built up on the surface of the polymer as a mass and heat transfer barrier and limits passage of degradation products from the matrix. The improved thermal stability can also be explained through the reduced mobility of the PVA chains. The decrease in thermal stability can be attributed to the fact that the clay itself has an ability to catalyze the degradation of the polymer matrix [24]. Thus the organoclay can be having two

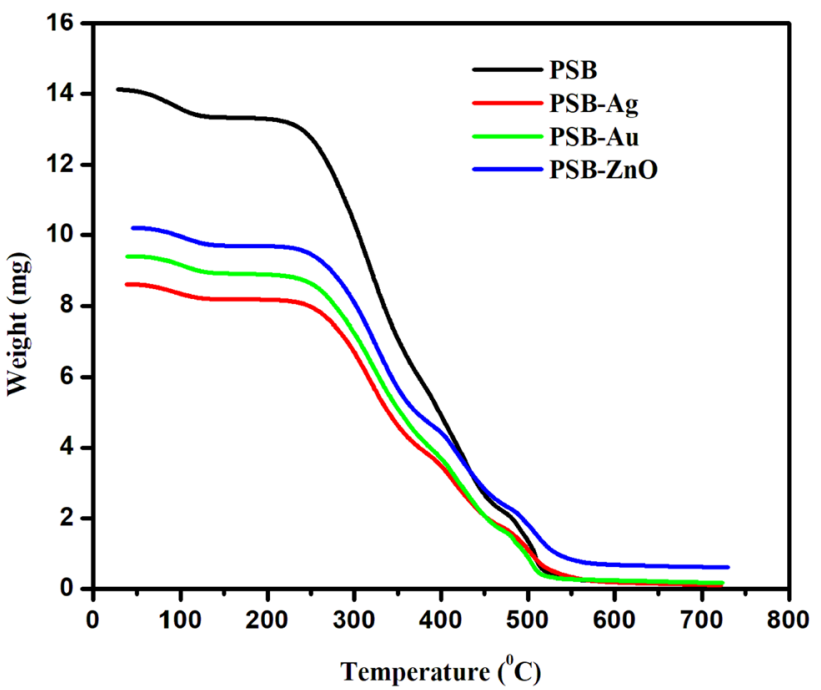

Fig. 4 TGA curve of polymer films

opposing functions in the thermal stability of the nanocomposite: a barrier effect, which should improve the thermal stability and a catalytic effect on the degradation of the polymer matrix, which decreases the thermal stability.

\subsection{Stability studies}

The polymer blend PSB and the nanocomposites PSB-Au, PSB-Ag and PSB-ZnO were incorporated in the Face mask formulation coded 1 and studied for sensory attributes, primary skin irritancy (safety) and physical stability test. Nickel containing nanocomposite PSB-NiO was excluded from the study due to cosmetic regulation [25]. Face mask formulation coded 1 with $1 \%$ loading of the samples (Codes 2, 3,4 and 5) were compared with the base face mask formulation for sensory and physical stability characteristics [26] (Table 6). The sensory evaluation showed that the PSB blend solution coded 2 showed almost equivalent match with the base mask formulations which suggests effective usage of the same in cosmetic products. On addition of nanoparticles to PSB, most of the parameters showed a substantial increase thereby pointing to

Table 5 Thermal properties of the polymer blend composites

\begin{tabular}{llll}
\hline Component & 1st peak & 2nd peak & $\begin{array}{l}\text { Final } \\
\text { residue } \\
(\%)\end{array}$ \\
\hline PSB & 230 & 470.20 & 1.24 \\
PSB-Au & 235 & 477.27 & 1.85 \\
PSB-ZnO & 237 & 480.05 & 6.01 \\
PSB-Ag & 235 & 487.95 & 2.11 \\
\hline
\end{tabular}




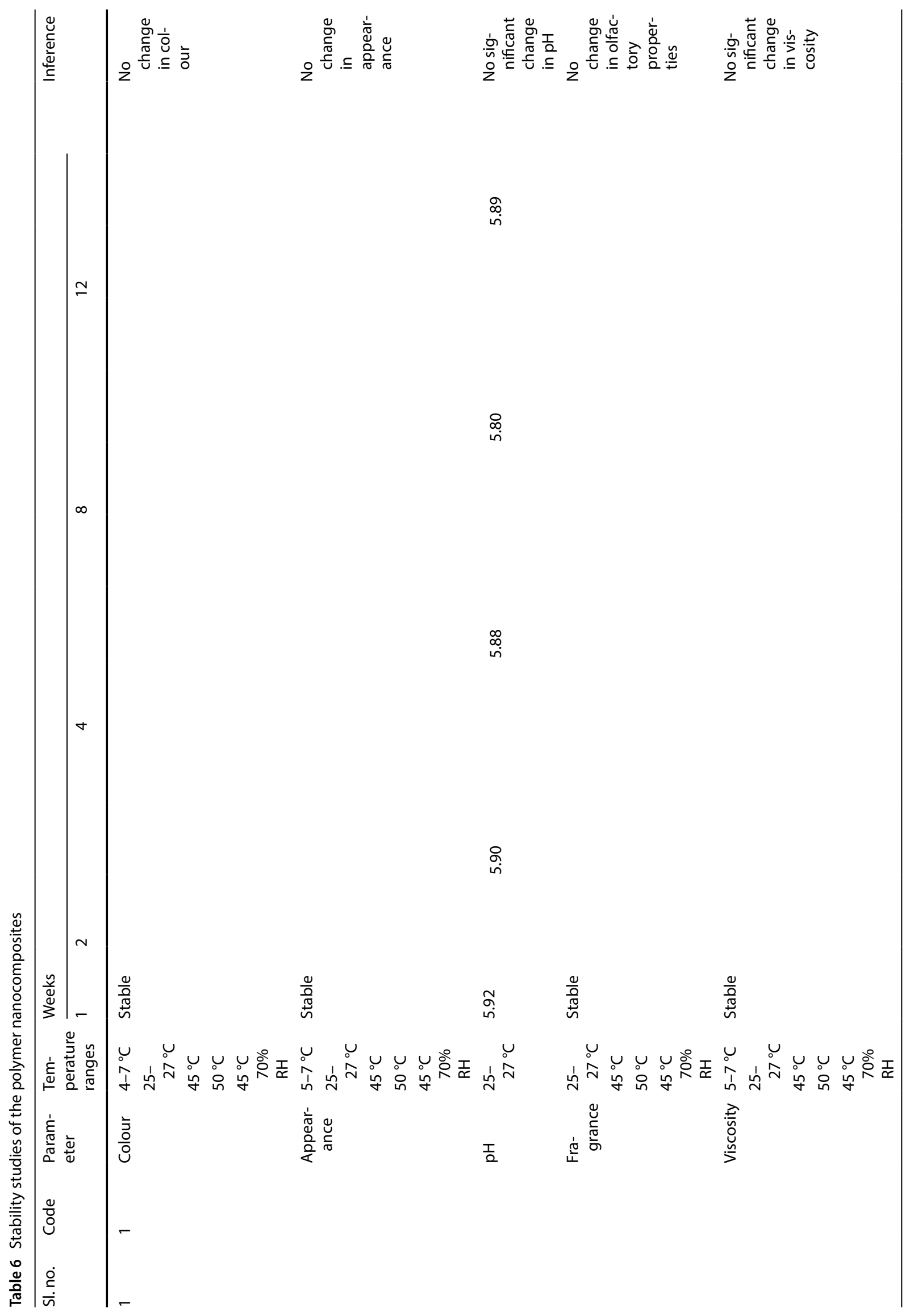




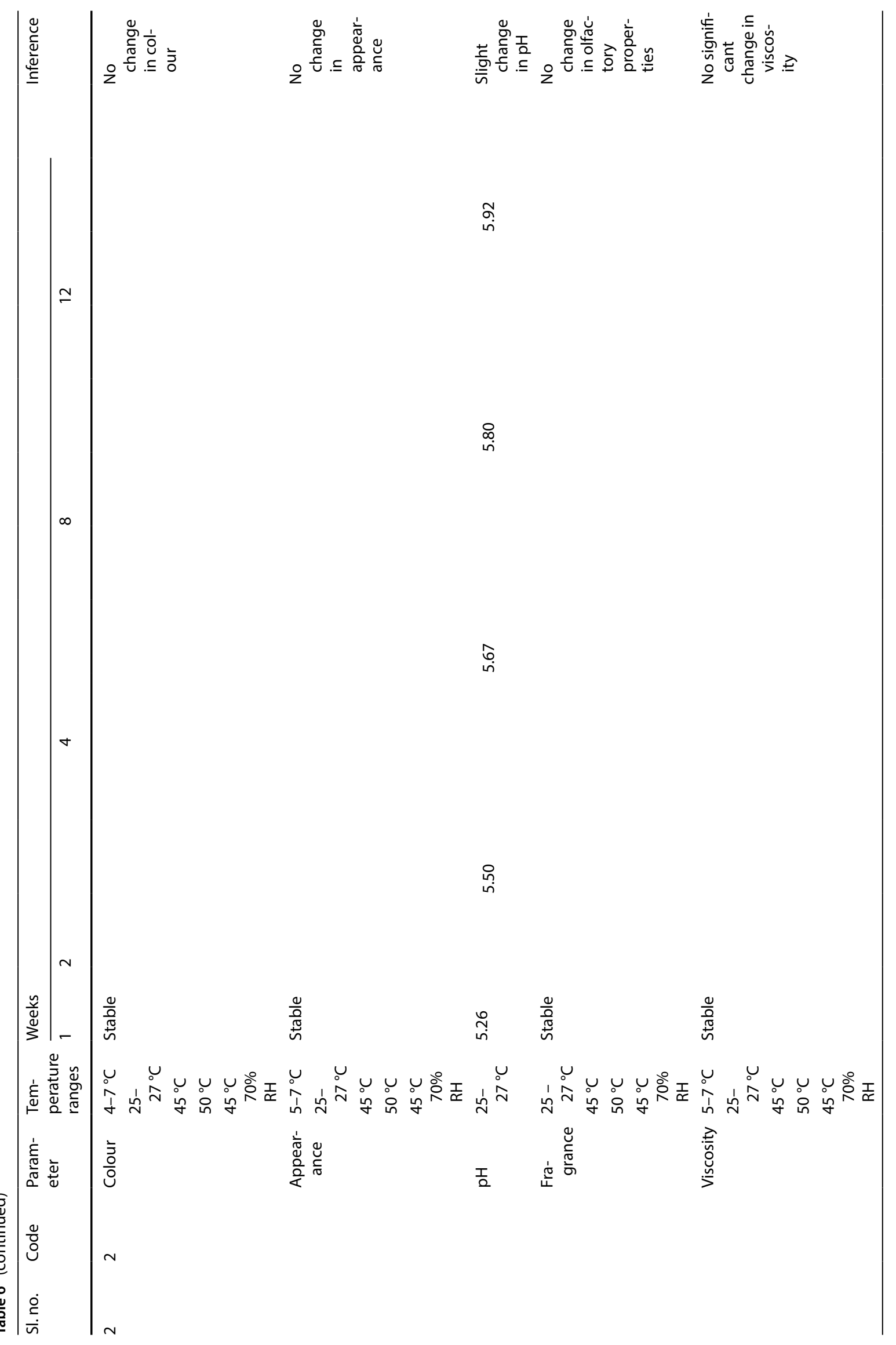

SN Applied Sciences

A SPRINGER NATURE journal 


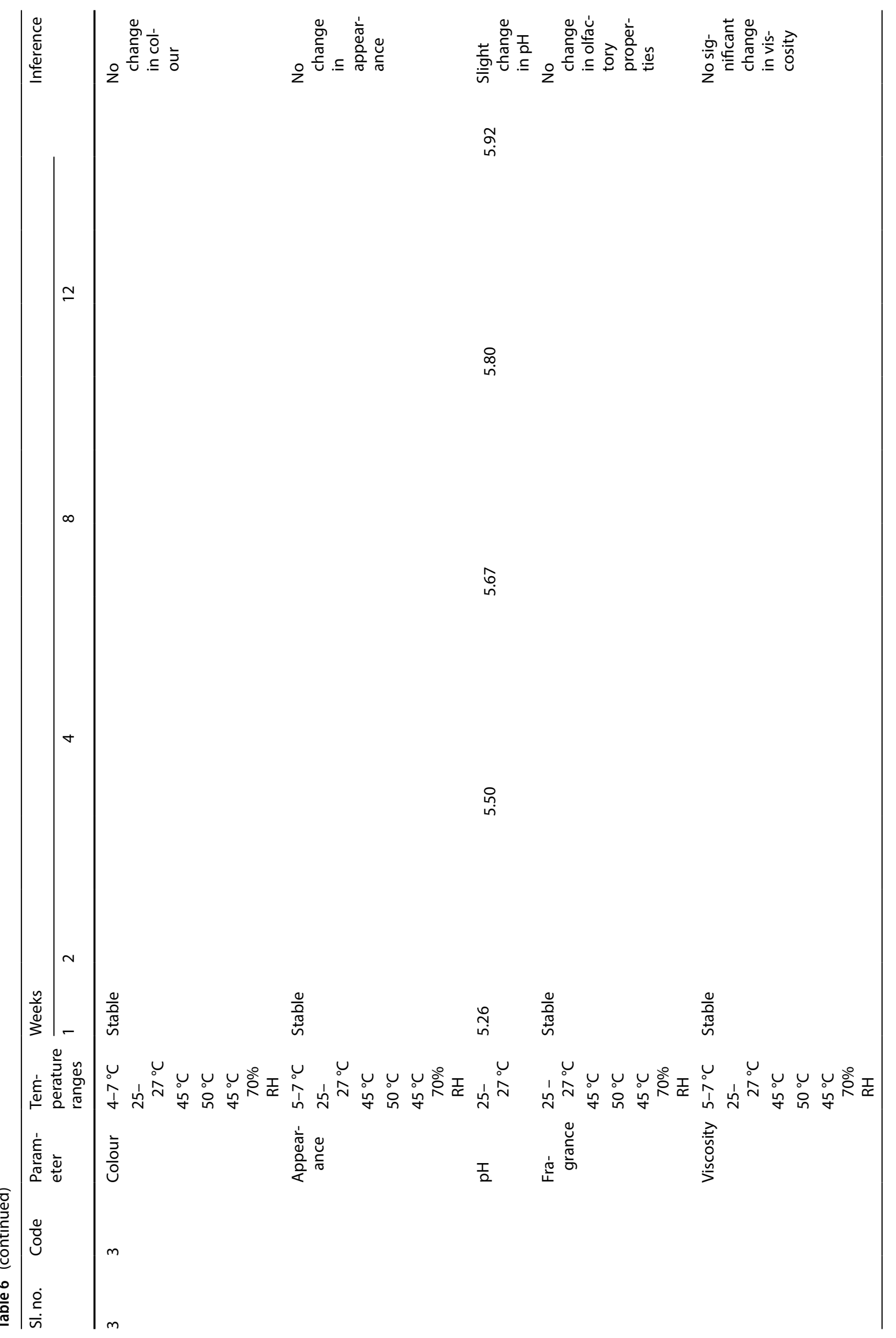




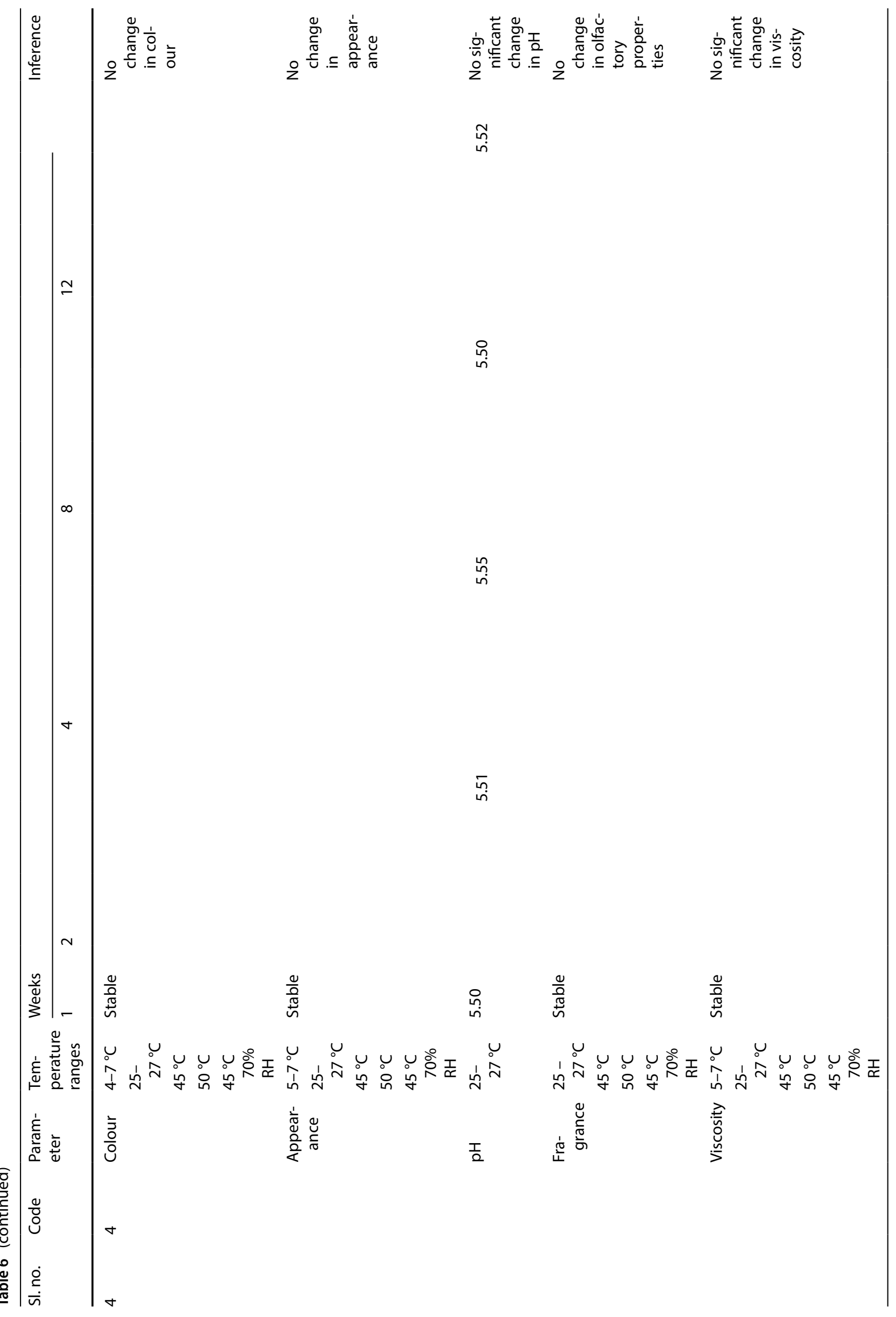

SN Applied Sciences

A SPRINGER NATURE journal 


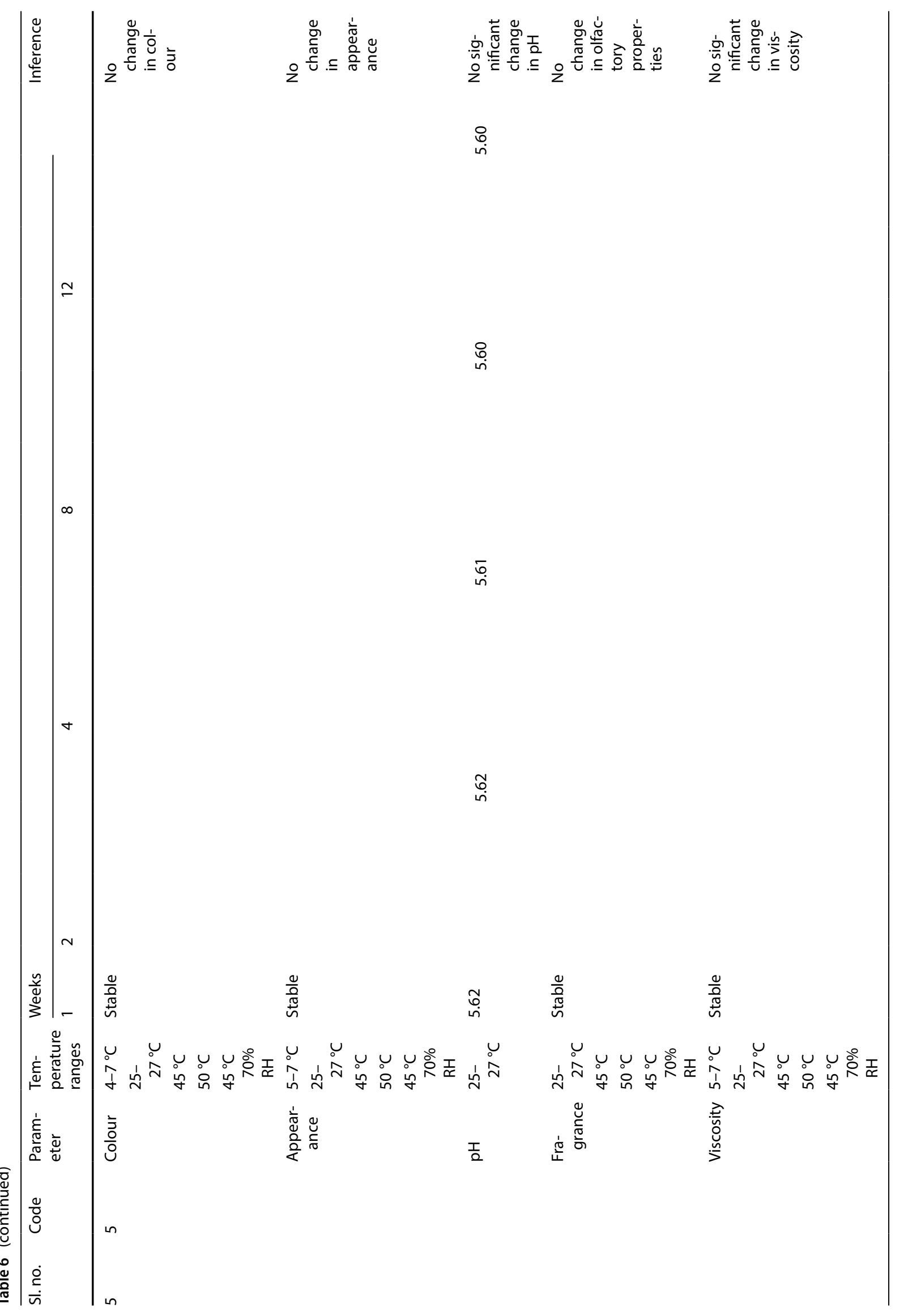


an enhancement of properties. The addition of gold nanoparticles to the polymer composite (code 3 ) is shown to reduce the skin irritation during use and feels smooth on the skin. After use of the formulations, the entire area of the facial skin projects an even skin tone and a non-oily look more effectively on usage of Code 5 . Code 3 with the gold nanoparticle shows greater skin brightness and lesser skin irritation. The composition coded 5 showed an increase in most of the sensory parameters as compared to the base face mask and also the polymer composite coded 2. This is in accordance with the already existing cosmetic-active properties of $\mathrm{ZnO}$ nanoparticles. The complete sensory evaluation at the time of use and after use is represented in the form of a cluster bar Figs. 5 and 6.

The physical stability test is decisive of a cosmetic products efficacy, performance and safety during its stipulated period of use. The parameters on which the physical stability of the product was assessed included fragrance, viscosity, appearance, $\mathrm{pH}$ and Colour. It was estimated at the temperature ranges of $4-7{ }^{\circ} \mathrm{C}, 25-27^{\circ} \mathrm{C}, 45^{\circ} \mathrm{C}, 50^{\circ} \mathrm{C}$ and at a relative humidity of $70 \%$. It was found to be stable for a period of 12 weeks for all the codes. The $\mathrm{pH}$ of the composition at room temperature was found to be in the range of 5.2-5.9.

\section{Conclusion}

PVA, starch and bentonite blend was functionalized with gold, silver and zinc oxide nanoparticles and the films were prepared by solution casting method. The prepared films were characterized by SEM and UV. The films showed good thermal stability and mechanical strength. The SEM micrograph shows slight agglomeration of the nanoparticles in the polymer matrix. These composites have been incorporated in the base face mask formulations and the studies reveal very good physical stability over a period of 12 weeks. The sensory parameters show enhanced properties for the nanoparticle reinforced blend as compared to pure blend. No irritation was found before and after using the face masks. This paves the way for an effective usage
Fig. 5 Sensory evaluation at the time of use

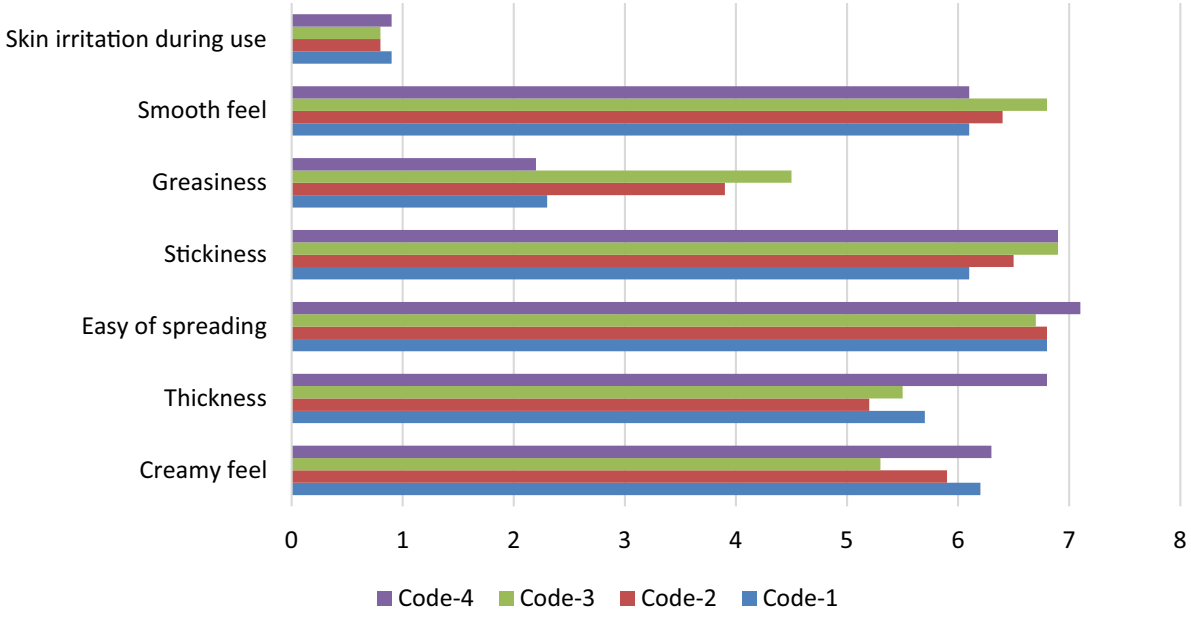

Fig. 6 Sensory evaluation after use

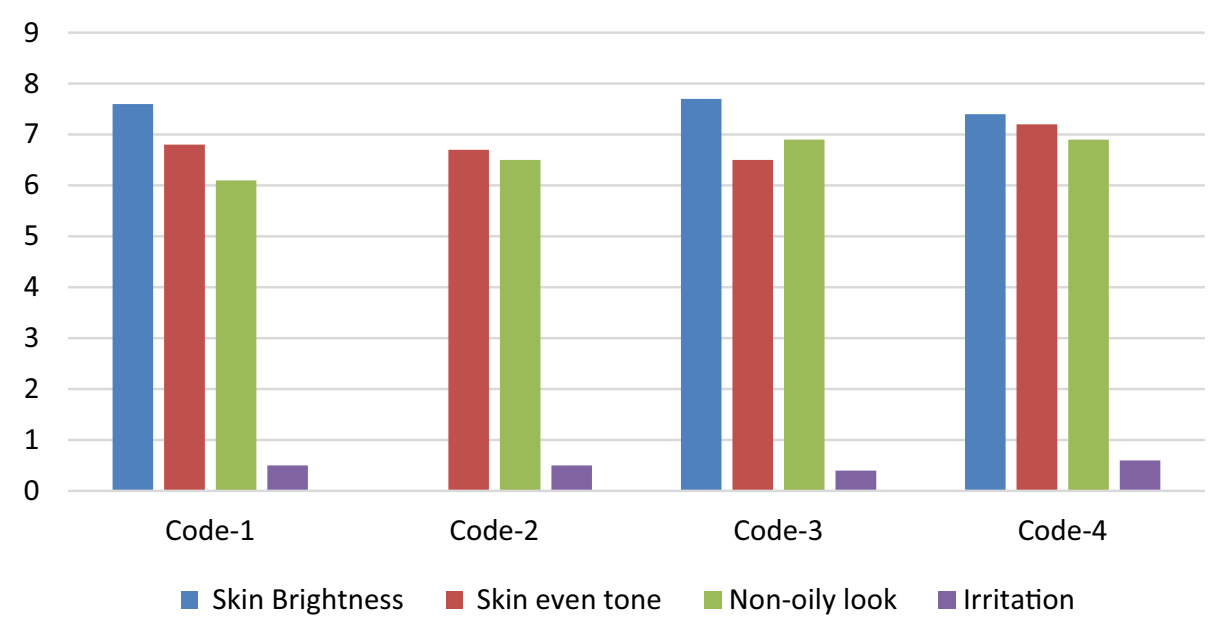


of these compositions in face masks to enhance the properties with only a $1 \%$ loading of the sample into the base face mask formulations.

Acknowledgements We would like to thank Ms. Meenakshi Narayanan and Mr. M. Pasupathi, CavinKare Research Centre for providing us with all the technical support we needed.

\section{Compliance with ethical standards}

Conflict of interest The authors declare that they have no conflict of interest.

\section{References}

1. Kalchounaki EK, Farhadi A, Zadehnazari A (2018) Preparation and properties evaluation of polyimide-matrix nanocomposites reinforced with glutamine functionalized multi-walled carbon nanotube. Polym Bull 75(12):5731-5744

2. Lagashetty A, Venkataramen I (2005) Polymer nanocomposites. Wiley, Hoboken

3. Vroman I, Tighzert L (2009) Biodegradable polymers. Materials 2(2):307-344

4. Tang X, Alavi S (2011) Recent advances in starch, polyvinyl alcohol based polymer blends, nanocomposites and their biodegradability. Carbohydr Polym 85(1):7-16

5. Râpă M, Grosu E, Stoica P, Andreica M, Hetvary M (2014) Polyvinyl alcohol and starch blends: properties and biodegradation behavior. J Environ Res Prot 11:34-42

6. Guo F, Aryana S, Han Y, Jiao Y (2018) A review of the synthesis and applications of polymer-nanoclay composites. Applied Sciences 8:1696-1725

7. Vieira RP, Fernandes $A R$, Kaneko TM, Consiglieri VO, Pinto CA, Pereira CS, Baby AR, Velasco MV (2009) Physical and physicochemical stability evaluation of cosmetic formulations containing soybean extract fermented by Bifidobacterium animalis. Braz J Pharm Sci 45:515-525

8. Beringhs AO, Rosa JM, Stulzer HK, Budal RM, Sonaglio D (2013) Green clay and aloe vera peel-off facial masks: response surface methodology applied to the formulation design. AAPS PharmSciTech. 14:445-455

9. Matike DME, Ekosse GIE, Ngole VM (2011) Physico-chemical properties of clayey soils used traditionally for cosmetics in Eastern Cape, South Africa. Int J Phy. Sci 6:7557-7566

10. Raj S, Jose S, Sumod US, Sabitha M (2012) Nanotechnology in cosmetics: opportunities and challenges. J Pharm Bioallied Sci 4:186-193

11. Smijs TG, Pavel S (2011) Titanium dioxide and zinc oxide nanoparticles in sunscreens: focus on their safety and effectiveness. Nanotechnol Sci Appl 4:95-112
12. Al-sherbini A, Ragab SS, El-Sayed HH (2015) Antimicrobial effects of silver nanoparticles mediated cosmetic cream and cotton gauze on candida strains. J Pharm Biol Sci 10:69-75

13. Taufikurohmah T, Rusmini IM, Baktir A, Syahrani A (2014) Synthesis of nanogold and stability test of this colloidal as essential material in drug, supplement and cosmetics. Int J Sci Res 3:60-63

14. Shalkevich N, Shalkevich A, Si-Ahmed L, Bürgi T (2009) Reversible formation of gold nanoparticle-surfactant composite assemblies for the preparation of concentrated colloidal solutions. Phys Chem Chem Phys 11:10175-10179

15. El-Nour KMA, Eftaiha AA, Al-Warthan A, Ammar RA (2010) Synthesis and applications of silver nanoparticles. Arab J Chem 3:135-140

16. Meena RK, Mandawat VK, Neeta G, Chouhan N (2017) Synthesis of $\mathrm{ZnO}$ nanoparticles for organic pollutant degradation. Int $J$ Adv Res Sci Eng 6:802-808

17. Abdullah OG, Salman YAK, Saleem SA (2015) In-situ synthesis of $\mathrm{PVA} / \mathrm{HgS}$ nanocomposite films and tuning optical properties. Mater Chem Phy 3:18-24

18. Moravkova T, Filip P (2016) Relation between sensory analysis and rheology of body lotions. Int J Cosmet Sci 38:558-566

19. Yap KCS, Aminah A (2011) Sensory analysis of lipstick. Int J Cosmet Sci 33:245-250

20. Baby AR, Migliato KF, Maciel CP, Zague V, Pinto CA, Salgado HR, Kaneko TM, Velasco MV (2007) Accelerated chemical stability data of O/W fluid emulsions containing the extract of Trichilia catigua Adr. Juss (and) Ptychopetalum olacoides Bentham. Revista Brasileira de Ciências Farmacêuticas 43:405-412

21. Chanshetty VB, Sangshetty K, Sharanappa G (2012) Surface morphology studies and thermal analysis of $\mathrm{V}_{2} \mathrm{O}_{5}$ doped polyaniline composites. Int J Eng Res Appl 2:611-616

22. Cupoletti J (2011) Nanocomposites and polymers with analytical methods. InTech

23. Sugimura $A$, Asai $M$, Matsunaga $T$, Akagi $Y$, Sakai T, Noguchi $H$, Shibayama M (2013) Mechanical properties of a polymer network of Tetra-PEG gel. Polymer journal. 45:300-306

24. Sadhu SD, Soni A, Garg M (2015) Thermal studies of the starch and polyvinyl alcohol based film and its nano composites. J Nanomedic Nanotechnol 7:1-5

25. Gandhi S (2012) Structural, mechanical and thermal properties of PVA-metal oxide nanocomposites. Ph.D. dissertation, Mahatma Gandhi University

26. Torres F, das Graças M, Melo M, Tosti A (2009) Management of contact dermatitis due to nickel allergy: an update. Clin Cosmet Investig Dermatol 2:39-48

Publisher's Note Springer Nature remains neutral with regard to jurisdictional claims in published maps and institutional affiliations. 